\title{
SOLAR VARIABILITY OVER THE PAST SEVERAL MILLENNIA
}

\author{
J. BEER ${ }^{1, *}$, M. VONMOOS ${ }^{1}$ and R. MUSCHELER ${ }^{2}$ \\ ${ }^{1}$ Swiss Federal Institute of Environmental Science and Technology (EAWAG), Ueberlandstrasse 133, \\ CH-8600 Dübendorf, Switzerland \\ ${ }^{2}$ NASA/Goddard Space Flight Center, Greenbelt, MD, USA \\ (*Author for correspondence: E-mail: beer@eawag.ch)
}

(Received 11 November 2005; Accepted in final form 28 February 2006)

\begin{abstract}
The Sun is the most important energy source for the Earth. Since the incoming solar radiation is not equally distributed and peaks at low latitudes the climate system is continuously transporting energy towards the polar regions. Any variability in the Sun-Earth system may ultimately cause a climate change. There are two main variability components that are related to the Sun. The first is due to changes in the orbital parameters of the Earth's position relative to the Sun induced by the other planets. Their gravitational perturbations induce changes with characteristic time scales in the eccentricity ( $\sim 100,000$ years), the obliquity (angle between the equator and the orbital plane) ( $\sim 40,000$ years) and the precession of the Earth's axis ( $\sim 20,000$ years). The second component is due to variability within the Sun. A variety of observational proxies reflecting different aspects of solar activity show similar features regarding periodic variability, trends and periods of very low solar activity (so-called grand minima) which seem to be positively correlated with the emitted energy from the Sun, the total and the spectral solar irradiance. The length of these records ranges from 25 years (solar irradiance) to 400 years (sunspots). In order to establish a quantitative relationship between solar variability and solar forcing it is necessary to extend the records of solar variability much further back in time and to identify the physical processes linking solar activity and total and spectral solar irradiance. The first step, the extension of solar variability, can be achieved by using cosmogenic radionuclides such as ${ }^{10} \mathrm{Be}$ in ice cores. After removing the effect of the changing geomagnetic field on the ${ }^{10} \mathrm{Be}$ production rate, a 9000 -year long record of solar modulation was obtained. Comparison with paleoclimatic data provides strong evidence for a causal relationship between solar variability and climate change. It will be the subject of the next step to investigate the underlying physical processes that link solar variability with the total and spectral solar irradiance.
\end{abstract}

Keywords: solar activity, solar influence on climate, cosmogenic radionuclides

\section{Introduction}

The Sun plays a central role for the Earth at least in two respects. Firstly, it is the gravitational centre around which the globe cruises on an elliptical orbit and secondly the Sun is by far the most important source of energy for the Earth system. Every second, the Sun looses 4.3 million tons of its mass, emitted in the form of electromagnetic radiation from the photosphere into space. This power is generated in the core by nuclear fusion and transported to the surface by radiative and convective processes. The Sun emits a total power of $4 \times 10^{26} \mathrm{~W}$ in the form of 


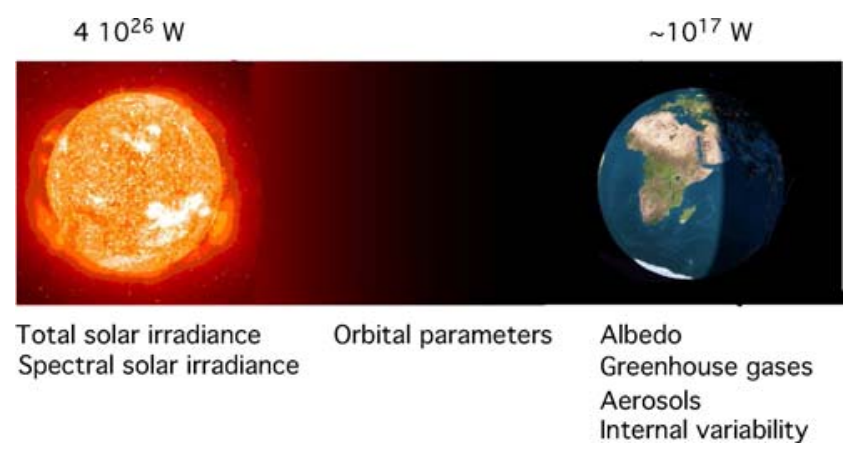

Figure 1. The Sun emits a total power of $4 \times 10^{26} \mathrm{~W}, 10^{17} \mathrm{~W}$ of which arrive at the Earth. When distributing this power homogeneously over the globe and taking into account that $30 \%$ is reflected (albedo), the average solar power amounts to $239 \mathrm{Wm}^{-2}$. Potential causes for changes in the solar radiation received by the Earth are: changes in the albedo of the Earth (cloud cover, ice and snow cover, vegetation), the atmospheric greenhouse gas concentration $\left(\mathrm{CO}_{2}, \mathrm{CH}_{4}\right.$ etc.), the atmospheric aerosol and dust content (volcanic eruptions, ashes, soot), and internal variability in the energy transport on Earth.

electromagnetic radiation with a spectrum that resembles a black body of $5700 \mathrm{~K}$. Because of the large distance between Sun and Earth $\left(150 \times 10^{6} \mathrm{~km}\right)$ and the relatively small radius of the Earth $(6370 \mathrm{~km})$, only about a billionth of this emitted power arrives at the top of the atmosphere $\left(1365 \mathrm{Wm}^{-2}\right)$. Taking into account that $30 \%$ of the arriving radiation is reflected back into space (albedo) and integrating over the cross section of the Earth, the total power received by the Earth system amounts to about $10^{17} \mathrm{~W}$ (Figure 1). In comparison, the contributions from other sources of energy such as cosmic ray particles $\left(10^{10} \mathrm{~W}\right)$, geothermal energy as a result of radioactive decay in the Earth interior and gravitational energy from the time of the Earth formation $\left(10^{13} \mathrm{~W}\right)$ and tidal energy $\left(10^{12} \mathrm{~W}\right)$, are negligible.

Considering the Earth as a black body and assuming steady state conditions, a simple calculation reveals a mean global temperature of $-18^{\circ} \mathrm{C}$ which is considerably lower than the effective value of $15^{\circ} \mathrm{C}$. The difference of $33^{\circ} \mathrm{C}$ is the result of the greenhouse gases in the atmosphere (natural greenhouse effect). As a consequence of the spherical shape of the Earth, the incoming solar power has its maximum at low latitudes $\left(1365 \mathrm{Wm}^{-2}\right)$ and decreases with the cosine of the latitude. This leads to a large energy gradient between equatorial and polar regions which the climate machine tries to remove by continuously transporting energy through the atmosphere and the ocean from low to high latitudes.

In principle, this could be a stable system consisting of a constant flow of solar energy arriving at Earth, distributed by the climate system and finally reemitted into space. However, in reality, the climate system is highly dynamic and never reaches equilibrium. As indicated in Figure 1 there are several potential causes for climate change:

- changes in the total solar irradiance (TSI) and its spectral distribution (SSI) 
- changes in the albedo (cloud and snow cover, vegetation etc.)

- changes in the optical properties of the atmosphere (greenhouse gases, aerosols, volcanic ash, dust etc.)

- internal variability within and between the various components of the climate system (e.g. changes in the ocean circulation)

We are faced with two main difficulties when dealing with the climate system. The first is its complexity, with many non-linear couplings that makes it very difficult to predict its behaviour without appropriate models. The second is its dynamics, with time scales ranging from seconds (atmospheric processes) to millions of years (evolution of the Sun, continental drift etc). This implies that the climate system has the potential to respond significantly to even very weak forcings and that this response may depend strongly, not only on the amplitude, but also on the duration of the forcing with potentially larger effects for longer lasting or repeated forcings. In this paper, we will concentrate on some aspects of solar variability on mainly millennial time scales.

\section{Solar Forcing: Orbital Parameters}

As discussed above, the amount of solar radiation arriving at the top of the atmosphere depends on the energy emitted by the Sun and the distance and orientation of the Earth with respect to the Sun. Let's begin with the latter. $99.85 \%$ of the mass of the solar system is concentrated in the Sun. The remaining $0.15 \%$ is distributed among the planets with Jupiter and Saturn taking the largest share (92\%). Consequently, the orbit of the Earth is dominated by the gravitational force of the Sun. However, the influence of the other planets cannot be neglected. These disturbing effects depend on the relative positions between Sun, Earth, and the other planets. Detailed calculations carried out by Milankovich (1930) and more recently by Berger (1978) and Laskar et al. (2004) reveal that gravitational forces of the planets influence three different orbital parameters of the Earth with different characteristic periodicities. These parameters are the eccentricity, the deviation of the Earth's orbit from a circle, the obliquity, the mean tilt angle of the Earth's axis relative to the ecliptic plane, and the precession of the Earth's rotational axis around the mean axis. The eccentricity changes with periodicities around 400,000 and 100,000 years, while changes in the obliquity occur with periodicities around 40,000 years and changes of the precession with 20,000 years. There are also shorter periodicities (Bertrand et al., 2002). However, these are too weak to have any significant effect on the climate.

Orbital forcing is special in at least two respects:

1. Only changes in the eccentricity lead to changes in the absolute amount of solar radiation received by the Earth. On the other hand, obliquity and precession affect only the relative distribution of the incoming radiation. 


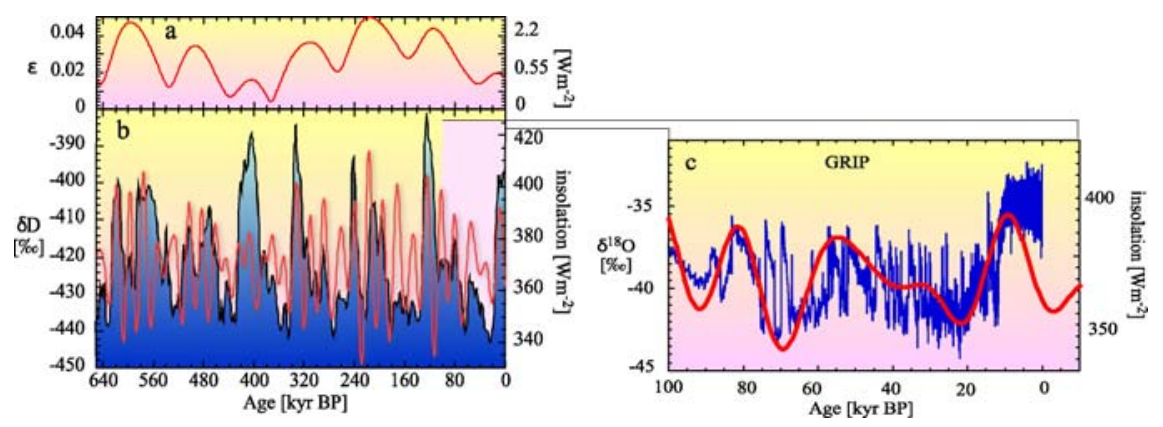

Figure 2. Orbital forcing and its effect on the climate. The gravitational forces of the planets (mainly Jupiter and Saturn) cause changes in the orbital parameters of the Earth that lead to changes in the total amount of solar radiation and its latitudinal distribution. Panel (a) shows the eccentricity, the deviation from a circular orbit for the past 640,000 years with a clear period of $\sim 100,000$ years which corresponds nicely with the sequence of glacial and interglacial periods found in the $\delta \mathrm{D}$ record from Dome C (Antarctica) (Spahni, 2005) that is an indicator of temperature shown in panel (b). Low $\delta \mathrm{D}$ values (blue curve) mean a depletion of the heavier hydrogen isotope $\mathrm{D}$ corresponding to colder climatic conditions. The red curve in panel (b) reflects the summer insolation at $65^{\circ} \mathrm{N}$ which includes, in addition to the eccentricity, the tilt angle (period of $\sim 40,000$ years) and the precession of the Earth's axis (period of $\sim 20,000$ years). Panel (c) shows a blow up of the past 100,000 years. Instead of $\delta \mathrm{D}$, here the $\delta^{18} \mathrm{O}$ record (blue curve) from the GRIP ice core (Johnsen et al., 1997) is plotted which also reflects the temperature. The abrupt short-term changes in $\delta^{18} \mathrm{O}$ (so-called Dansgaard-Oeschger events) are most probably due to melt-water pulses shutting down the deep-water formation in the North Atlantic. It is interesting to note that the change in the insolation for the coming 10,000 years is comparatively small.

2. Orbital forcing is the only forcing that can be calculated precisely for the past and even the future several million years because it is based purely on celestial mechanics.

As an example, Figure 2 shows the eccentricity (panel a) and the summer insolation (red curve) at $65^{\circ} \mathrm{N}$, together with the $\delta \mathrm{D}$ record (in blue) from the Dome $\mathrm{C}$ ice core, Antarctica (Spahni, 2005) (panel b). $\delta \mathrm{D}$, the deviation of the isotopic ratio $\mathrm{D} / \mathrm{H}$ from a standard value, is a proxy of the temperature, with low values indicating cold conditions. The strongest correspondence between $\delta \mathrm{D}$ and the insolation is in the 100,000 years band caused by the eccentricity changes. Note that the mean annual global insolation changes caused by the eccentricity are very small $\left(<2.5 \mathrm{Wm}^{-2}\right)$ (panel a).

In panel (c) of Figure 2, the past 100,000 years and the future 10,000 years of insolation at $65^{\circ} \mathrm{N}$ are depicted together with $\delta^{18} \mathrm{O}$ (blue curve), another temperature proxy measured in the GRIP ice core from Greenland (Johnsen et al., 1997). The comparison shows a generally good agreement between orbital forcing and climate response. However, during the glacial period from 80,000 to 10,000 years before present, the $\delta^{18} \mathrm{O}$ record is characterized by abrupt climate changes that are usually attributed to fluctuations in the thermohaline circulation of the ocean (Broecker, 1997). During such an event, the mean annual temperature drops by about $20^{\circ} \mathrm{C}$ 
in Greenland within a decade or two. Other interesting features in Figure 2c are that the decrease of the insolation during the past 10,000 years is not visible in the isotopic record and that insolation changes are not predicted to play an important role in the next 10,000 years.

We conclude this short discussion of the orbital forcing with one last interesting fact. During the past 650,000 years, by far the largest signal induced by insolation changes is the 100,000 years cycle of glacial-interglacial periods (Figure 2b). However, the corresponding mean annual forcing changes are extremely small (Figure 2a).

\section{Solar Variability}

Solar variability has only recently been considered to be a potential forcing factor of climate change. This is also reflected by the fact that the term "solar constant" is still widely used to describe the total solar irradiance (TSI). This may be somewhat surprising given the fact that the Sun provides the power which drives the climate system. Nevertheless, there were a few scientists who recognised the importance of this issue a long time ago. Among others, Abbot (1910) tried hard to detect fluctuations in the solar constant from the Earth's surface. However, he failed since changes in the optical properties of the atmosphere inhibit the detection of the relatively small TSI changes from the Earth's surface. A new era began when Eddy (1976) pointed to the striking similarity between the winter severity index of Paris and London and proxies for solar activity, as for example the sunspot record or changes of the atmospheric concentration of the cosmogenic radionuclide ${ }^{14} \mathrm{C}$ measured in tree rings.

But only after it was possible to operate radiometers outside the atmosphere on satellites, did it become clear that indeed the solar constant is not constant (Fröhlich, 2006). However, the observed changes of the TSI over an 11-year cycle are very small $(0.1 \%)$, corresponding to an average temperature change of $1.5 \mathrm{~K}$ of the photosphere and, on Earth, to a global forcing change of $0.25 \mathrm{Wm}^{-2}$ (averaging over the globe and taking into account the albedo of 30\%). This led many people to conclude that, even if the solar constant is not constant, the changes are too small to be climatically relevant without invoking additional strong amplification mechanisms. This conclusion seems to be premature, firstly because there is no doubt that there are positive feedback mechanisms in the climate system. A cooling for example, leads to growing ice sheets which increases the albedo and thus the cooling. The existence of feedback mechanisms is illustrated by the discussed glacial-interglacial cycles that are related to a very weak annual mean change in insolation. General circulation models show that a change of the TSI by $0.1 \%$ over decades to centuries is not negligible (Cubash and Voss, 2000). Last but not least, the change of $0.1 \%$ in the TSI is accompanied by far greater changes in 
the UV part of the solar spectrum (Rottman, 2006) causing changes in the stratosphere which can be coupled down to the troposphere (Haigh, 2006). Secondly, it could be misleading to extrapolate from just three decades of TSI observations to centennial and millennial time scales. There are no physical reasons why the emission of radiation from the Sun should not show larger fluctuations on longer time scales up to $3 \times 10^{7}$ years (Helmholtz-Kelvin time scale). Other stars, although not exactly of the same type as the Sun, show considerably larger fluctuations (Radick, 2001).

In the past years, large efforts have been made to model the TSI by combining brightening (faculae and magnetic networks) and darkening (sunspots) effects related to the magnetic activity on the Sun (Solanki, 2006). Although successful in reproducing the short-term variability over the past few decades, these models are unable to predict the full potential range of solar variability unless we know more about the solar conditions (TSI, open and closed magnetic flux) during a period of very low solar activity such as the Maunder Minimum (1645-1715 AD) when the sunspots were almost completely absent (Lockwood, 2006). To reach the ambitious goal of reconstructing the total and spectral solar irradiance over decadal to millennial time scales, we need to know more about the physical conditions of the Sun in the past. We also have to develop physical models of how these conditions are related to the TSI and to the SSI. Here, we will focus on the first task: the reconstruction of long-term solar variability inferred from cosmogenic radionuclide records.

\section{Reconstruction of Long-Term Solar Variability}

There are several proxies of solar activity which are all based on direct measurements or on observations and are therefore called direct proxies. They have in common that they are all related - even though in different ways - to magnetic processes on the Sun with temporal resolutions of weeks to years and that they are generally more reliable for more recent times. Depending on their length, all the records show similar features (Figure 3): the 11-year Schwabe cycle, a long-term trend from 1900-1950 with a generally increasing activity with time and some short periods (1-7 decades) with reduced solar activity. The most pronounced is the Maunder Minimum (1645-1715 AD) which is characterised by an almost complete absence of sunspots (Eddy, 1976) (pink band in Figure 3). A more detailed comparison shows that, apart from these common features, there are also clear differences, mainly due to the fact that all these proxies are related in various ways to different aspects of magnetic processes taking place on the Sun. Two records do not extend to the present. The reasons are that, to our knowledge, aurorae were no longer counted after 1955, and that the ice core which was analyzed for ${ }^{10} \mathrm{Be}$ (see below) was drilled in 1985 . 


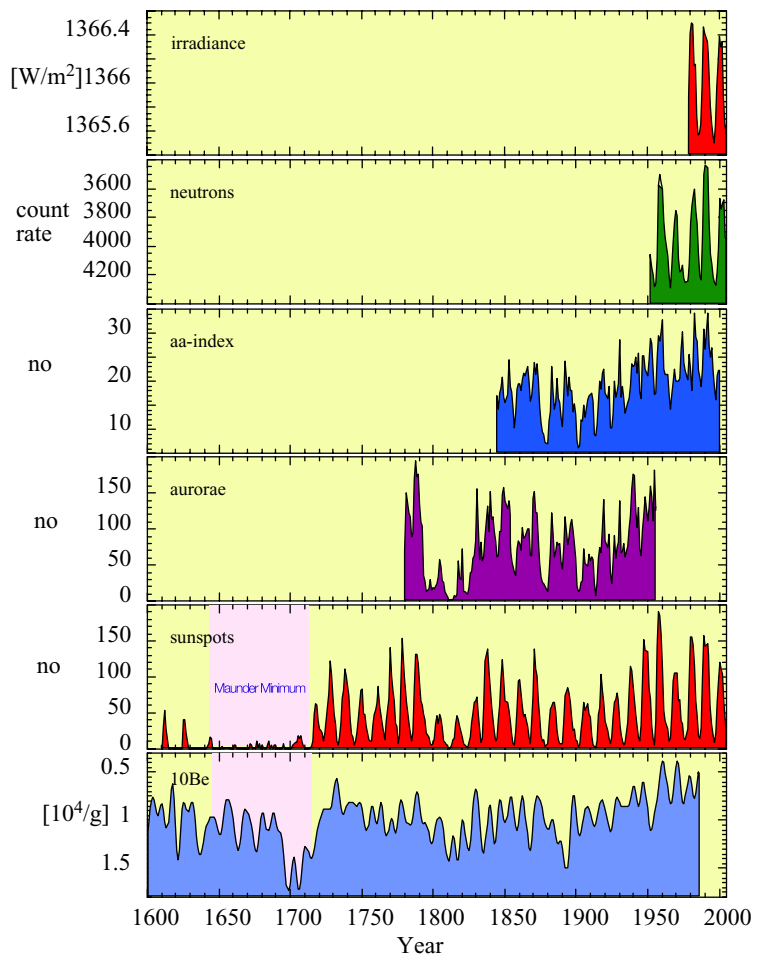

Figure 3. Comparison of proxies of solar activity. Each proxy reflects a specific aspect of solar activity. As a result, all proxies show some common features (11-year cycle, trends, solar minima), but also differences. The length is limited to the periods of instrumental observations and ranges from 25 years (TSI) to about 400 years (sunspots). No aurora counts could be found for the period since 1955. ${ }^{10} \mathrm{Be}$ is the only record which is not based on direct observations and, therefore has the potential to be extended over at least 10,000 years. The Dye 3 ice core used for the ${ }^{10} \mathrm{Be}$ analysis was drilled in 1985 (Beer et al., 1990).

The only record in Figure 3, which is not based on direct observations, is the ${ }^{10} \mathrm{Be}$ record (Beer et al., 1994). ${ }^{10} \mathrm{Be}$ and other cosmogenic radionuclides such as ${ }^{14} \mathrm{C}$ and ${ }^{36} \mathrm{Cl}$ offer the unique opportunity to extend the reconstruction of solar activity back to at least 10,000 years. Cosmogenic radionuclides are produced in the Earth's atmosphere by the interaction of galactic cosmic rays (GCR) with nitrogen, oxygen, and argon. Before reaching the Earth, GCR have to cross the heliosphere where they are subject to solar induced modulation effects. The propagation of GCR through the heliosphere is described by the cosmic ray transport equation formulated by Parker (1965). To reduce the complexity, several simplifying assumptions have been introduced leading to the so-called force field equation (Gleeson and Axford, 1967). It shows that the effect of solar activity on the energy spectrum of galactic cosmic rays can be described by the so-called solar modulation function $\Phi$ (Figure 4).

Figure 4 illustrates the enhanced shielding effect during periods of high solar activity, i.e. the enhanced energy loss of the low energy GCR protons due to 


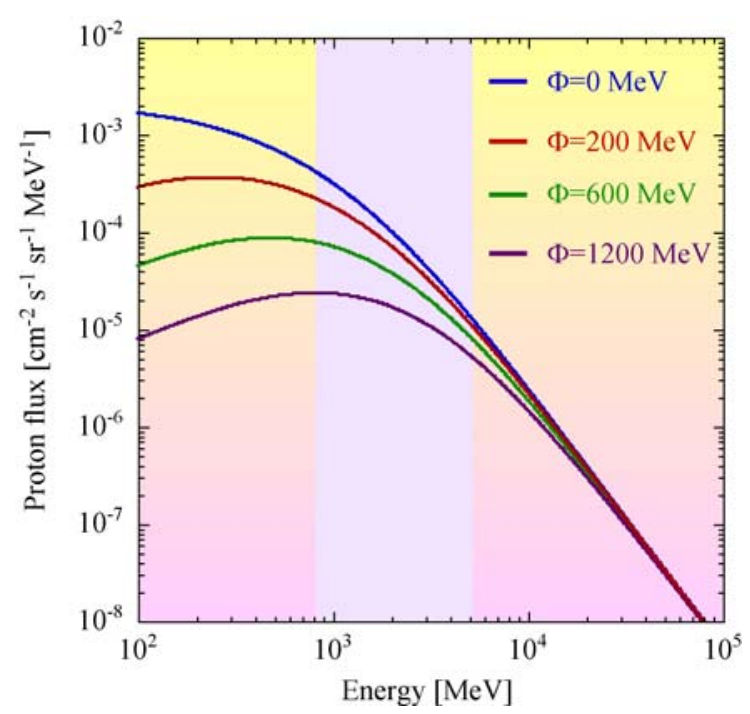

Figure 4. Differential energy spectra for the flux of galactic cosmic ray protons arriving at the top of the atmosphere. As a result of solar modulation during the propagation through the heliosphere, the flux is reduced depending on the intensity of the solar modulation expressed by the parameter $\Phi$ (Masarik and Beer, 1999). The light blue band indicates the energy range that is mainly responsible for the production of ${ }^{10} \mathrm{Be}$ in the atmosphere.

the increased intensity of the magnetic field carried by the solar wind. The solar modulation affects mainly the GCR protons with energies below $10^{4} \mathrm{MeV}$. This coincides with the most efficient energy range for the subsequent production of the cosmogenic radionuclide ${ }^{10} \mathrm{Be}$ from GCR in the Earth's atmosphere, which covers the range 0.8-5 GeV (McCraken, 2004; Webber and Higbie, 2003) (light blue band in Figure 4). This makes ${ }^{10} \mathrm{Be}$ time series sensitive recorders of solar modulation in the past and, thus, of the temporal changes of solar variability.

The production rate of cosmogenic radionuclides also depends on the shielding effect of the geomagnetic field. As the geomagnetic modulation of cosmic rays is mainly due to the Earth's dipole field, the shielding effect is highly dependent on the geomagnetic latitude, being maximal at low latitudes. The production rate of cosmogenic radionuclides as a function of geomagnetic and heliospheric modulations is well understood and can be simulated using Monte Carlo technique (Masarik and Beer, 1999; Webber and Higbie, 2003). Figure 5 shows the dependence of the global mean ${ }^{10} \mathrm{Be}$ production rate as a function of the geomagnetic field intensity and the solar modulation function $\Phi$.

Subsequent to its production, ${ }^{10} \mathrm{Be}$ becomes attached to aerosols and follows their pathways. After a mean residence time of $1-2$ years, ${ }^{10} \mathrm{Be}$ is removed from the atmosphere, mainly by wet deposition, and stored in natural archives such as 


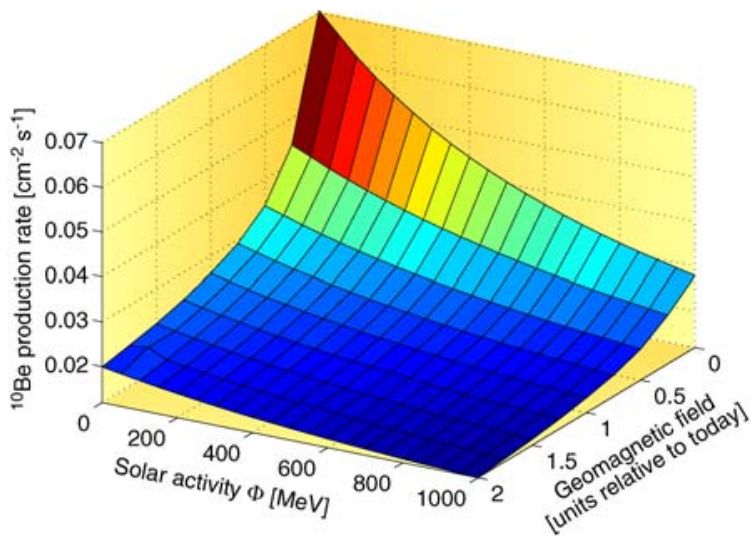

Figure 5. Dependence of the ${ }^{10} \mathrm{Be}$ production rate on the intensity of the geomagnetic dipole field in relative units, and on the solar modulation function $\Phi$ (Masarik and Beer, 1999).

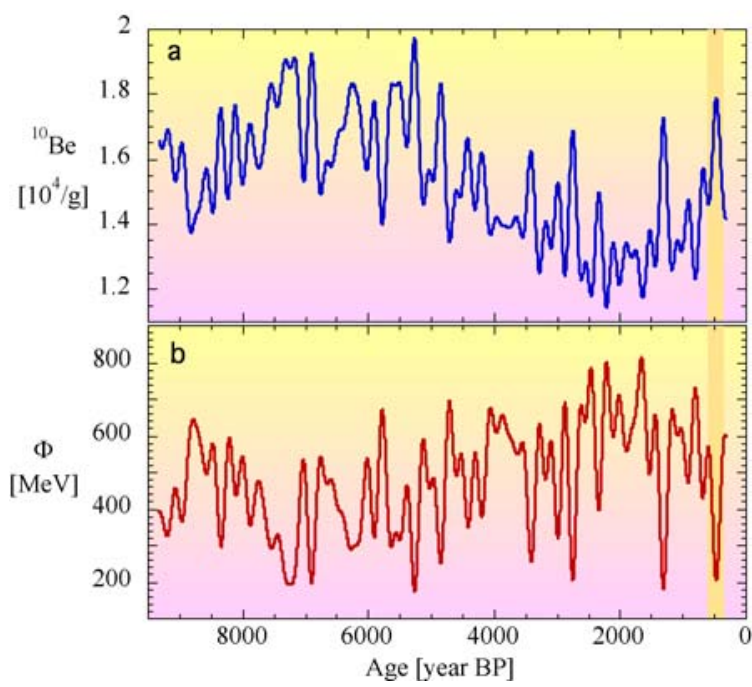

Figure 6. Derivation of the solar modulation function $\Phi$ from the measured ${ }^{10}$ Be concentration. Panel (a): Measured ${ }^{10} \mathrm{Be}$ concentration in the GRIP ice core from Greenland after applying a low-pass filter with a cut-off frequency of $1 /(200$ years $)$ to remove system effects caused by the transport of ${ }^{10} \mathrm{Be}$ from the atmosphere into the ice. Panel $(b)$ : Reconstructed solar modulation function $\Phi$ derived from the ${ }^{10} \mathrm{Be}$ record of panel (a). The production contribution from the geomagnetic field (not shown) has been removed using the dependence of the ${ }^{10} \mathrm{Be}$ production rate on the geomagnetic field intensity and $\Phi$ shown in Figure 5 (Vonmoos et al., 2006).

ice caps. Therefore, cosmogenic radionuclides provide information on the solar magnetic activity with a maximal temporal resolution of 1 year on a time range depending on the half-life and the age of the investigaed archive. Figure 6a depicts the measured ${ }^{10} \mathrm{Be}$ concentration record of the GRIP ice core in Central Greenland (Muscheler et al., 2004) after applying a low-pass filter with a cut-off frequency of 
$1 /(200$ years) to remove transport and deposition effects. The remaining signal is still composed of a component caused by changes in the intensity of the geomagnetic dipole field and a component related to the solar modulation we are looking for. To remove the geomagnetic dipole component, we use an independently determined record of the paleomagnetic field intensity and apply the relationship between the ${ }^{10} \mathrm{Be}$ production rate, which is proportional to the measured ${ }^{10} \mathrm{Be}$ concentration, the magnetic field intensity, and the solar modulation function $\Phi$ shown in Figure 5 (Vonmoos et al., 2006). The resulting solar modulation record is shown in panel (b) of Figure 6.

The $\Phi$-record is characterized by a high and persistent variability throughout the Holocene. A period of relatively high solar activity around 8000 years BP is followed by a decrease reaching a minimum around 7000 years BP. After a slow but steady increase, $\Phi$ reaches another longer lasting maximum around $2000 \mathrm{BP}$ (Roman period) before decreasing again. Superimposed to these slow changes are abrupt short-term troughs, some of which very pronounced, with $\Phi$ values around $200 \mathrm{MeV}$ and lasting about a century. These are called grand minima. A well-known example is the Spoerer Minimum (1415-1535 AD), indicated by the yellow band in Figure 6. Note that the top of the ice core corresponds to $1645 \mathrm{AD}$ and therefore does not show the Maunder Minimum (1645-1715 AD).

\section{Solar Variability and Solar Forcing}

This record of solar modulation provides the basis from which, in a next step, the TSI, and hopefully also the SSI, can be derived (Lockwood, 2006). This is a difficult task with still many open questions. A rapidly growing number of paleoclimate records reveals evidence that a relationship does indeed exist between solar magnetic activity and solar irradiance (Fröhlich, 2006). For example, Figure 7 shows the relationship between the relative amount of ice rafted debris in a sediment core from the North Atlantic (Bond et al., 2001) and the reconstructed solar modulation of Figure 6 after applying a low pass filter with a cut-off frequency of $1 /(900$ years). This "ice rafted debris" consists of specific glass particles which originate from volcanic eruptions in Iceland. They are picked up by glaciers moving towards the coast where they break up into icebergs and drift southwards carrying the particles. During the melting of the iceberg, the particles are released, sink to the bottom, and are incorporated into the sediment. The distance an iceberg can drift south before melting depends on the prevailing climate conditions (surface winds and surface hydrography). The close correlation between the amount of glass particles produced by volcanic eruptions in Iceland and the solar modulation function $\Phi$ clearly points to a causal relationship. Some of the discrepancies are due to the dating uncertainties of the two cores. Similar relationships have been found with the regional precipitation rate by analyzing stalagmites in a cave in Oman (Neff et al., 2001), with the advances and retreats of glaciers (Denton and 


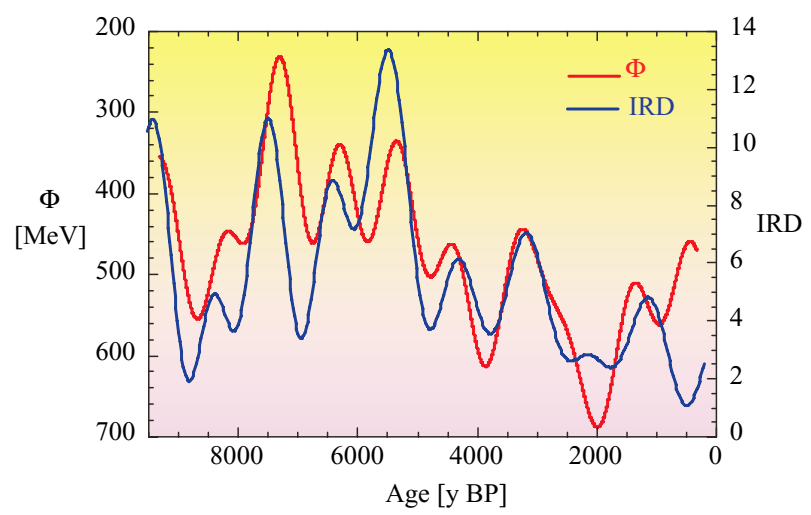

Figure 7. Comparison of the reconstructed solar modulation function $\Phi$ of Figure 6 with ice rafted debris (IRD) retrieved from a sediment core in the North Atlantic (Bond et al., 2001). In this figure, the $\Phi$ record has been low-pass filtered with a cut-off frequency of 1/(900 years) and is plotted inversely compared to Figure 6. The ice rafted debris consists of glass particles originating from volcanic eruptions in Iceland. Incorporated into icebergs, they drift much further south during periods of low solar activity.

Karlén, 1973) and the water level of lakes in the French Jura (Holzhauser, 1997). These are just a few examples of a rapidly growing number of publications in this field.

\section{Conclusions}

It is well known that the Sun plays the fundamental role as our energy source. However, it is still an open question what role the Sun plays in climate change. Direct measurements of the total (TSI) and the spectral (SSI) irradiance using satellite born radiometers show relatively small changes in accordance with the solar magnetic activity. To answer this question, we have (1) to understand the physical mechanisms responsible for the irradiance changes, (2) to reconstruct the solar variability over the past millennia, (3) to derive from this variability record, reliable estimates of the TSI and SSI changes, and (4) to determine the response of the climate system using appropriate models. As far as the second topic is concerned we can rely on a variety of solar activity proxies based on direct observations (sunspots, $a a$-index, aurorae). However, all of them are limited to periods ranging from a few decades to a few centuries. To date, the only proxy providing information about the solar variability on millennial time scales are cosmogenic radionuclides stored in natural archives such as ice cores. They clearly reveal that the Sun varies significantly on millennial time scales and most likely plays an important role in climate change. 


\section{Acknowledgements}

The authors would like to thank R.-M. Bonnet for very valuable comments. This work was supported by the Swiss National Science Foundation.

\section{References}

Abbot, C. G.: 1910, 'The solar constant of radiation', Annual Report of the Smithsonian Institution, 319 pp.

Beer, J., Blinov, A., Bonani, G., Finkel, R. C., Hofmann, J. J., et al.: 1990, 'Use of ${ }^{10}$ Be in polar ice to trace the 11-year cycle of solar activity', Nature 347, 164-166.

Beer, J., Baumgartner, S., Hannen-Dittrich, B., Hauenstein, J., Kubik, P., et al.: 1994, 'Solar Variability Traced by Cosmogenic Isotopes', in J. M. Pap, C. Fröhlich, H. S. Hudson, and S. K. Solanki (eds.), The Sun as a Variable Star: Solar and Stellar Irradiance Variations, Cambridge University Press, Cambridge, pp. 291-300.

Berger, A.: 1978, 'Long-term variations of daily insolation and quaternary climatic changes', J. Atmos. Sci. 35, 2362-2367.

Bertrand, C., Loutre, M.-F., and Berger, A.: 2002, 'High frequency variations of the Earth's orbital parameters and climate change', Geophys. Res. Lett. 29, doi:10.1029/2002GL015622.

Bond, G., Kromer, B., Beer, J., Muscheler, R., Evans, M. N., et al.: 2001, 'Persistent solar influence on north Atlantic climate during the Holocene', Science 294, 2130-2136.

Broecker, W. S.: 1997, 'Thermohaline circulation, the Achilles heel of our climate system: Will man-made $\mathrm{CO}_{2}$ upset the current balance?', Science 278, 1582-1588.

Cubasch, U. and Voss, R.: 2000, 'The influence of total solar irradiance on climate', Space Sci. Rev. 94, 185-198.

Denton, G. H. and Karlén, W.: 1973, 'Holocene climatic variations - their pattern and possible cause', Quat. Res. 3, 155-205.

Eddy, J. A.: 1976, 'The maunder minimum', Science 192, 1189-1201.

Fröhlich, C.: 2006, 'Solar irradiance variability since 1978', Space Sci. Rev., this volume, doi: 10.1007/s11214-006-9046-5.

Gleeson, L. J. and Axford, W. I.: 1967, 'Cosmic rays in the interplanetary medium', Astrophys. J. 149, L115-L118.

Haigh, J.: 2006, 'Solar influences on dynamical coupling between the stratosphere and troposphere', Space Sci. Rev., this volume, doi: 10.1007/s11214-006-9067-0.

Holzhauser, H.: 1997, 'Gletscherschwankungen innerhalb der letzten 3200 Jahre am Beispiel des grossen Aletsch- und des Gornergletschers. Neue Ergebnisse', in B. Salm (ed.), Gletscher im ständigen Wandel, VDF-Hochschulverlag AG, Zürich.

Johnsen, S. J., Clausen, H. B., Dansgaard, W., Gundestrup, N. S., Hammer, C. U., et al.: 1997, 'The $\delta^{18} \mathrm{O}$ record along the Greenland Ice Core Project deep ice core and the problem of possible Eemian climatic instability', J. Geophys. Res. 102, 26,397-26,410.

Laskar, J., Robutel, P., Joutel, F., Gastineau, M., Correia, A. C. M., and Levrard, B.: 2004, 'A longterm numerical solution for the insolation quantities of the Earth', Astron. Astrophys. 428, $261-$ 285.

Lockwood, M.: 2006, 'What do cosmogenic isotopes tell us about past solar forcing of climate?', Space Sci. Rev., this volume, doi: 10.1007/s11214-006-9049-2.

Masarik, J. and Beer, J.: 1999, 'Simulation of particle fluxes and cosmogenic nuclide production in the Earth's atmosphere', J. Geophys. Res. 104, 12,099-12,111. 
McCracken, K. G.: 2004, 'Geomagnetic and atmospheric effects upon the cosmogenic Be-10 observed in polar ice', J. Geophys. Res. 109, doi:10.1029/2003JA010060.

Milankovich, M.: 1930, 'Mathematische Klimalehre und atsronomische Theorie der Klimaschwankungen', in W. Köppen and R. Geiger (eds.), Handbuch der Klimatologie, Gebrüder Bornträger, Berlin, pp. 1-176.

Muscheler, R., Beer, J., Wagner, G., Laj, C., Kissel, C., et al.: 2004, 'Changes in the carbon cycle during the last deglaciation as indicated by the comparison of ${ }^{10} \mathrm{Be}$ and ${ }^{14} \mathrm{C}$ records', Earth Planet. Sci. Let. 219, 325-340.

Neff, U., Burns, S., Mangini, A., Mudelsee, M., Fleitmann, D., and Matter, A.: 2001, 'Strong coherence between solar variability and the monsoon in Oman between 9 and 6 kyrs ago', Nature 411, 290 293.

Parker, E. N.: 1965, 'The passage of energetic charged particles through interplanetary space', Planet. Space Sci. 13, 9-49.

Radick, R. R.: 2001, 'A brief survey of chromospheric and photometric variability among sunlike stars', Adv. Space Res. 26, 1739-1745.

Rottman, G.: 2006, 'Measurements of total and spectral solar irradiance', Space Sci. Rev., this volume, doi: 10.1007/s11214-006-9045-6.

Solanki, S. K.: 2006, 'Solar variability of possible relevance for planetary climates', Space Sci. Rev., this volume, doi: 10.1007/s11214-006-9044-7.

Spahni, R., Chappellaz, J., Stocker, T. F., Loulergue, L., Hausammann, G., et al.: 2005, 'Atmospheric methane and nitrous oxide of the late Pleistocene from Antarctic ice cores', Science 310, 1317 1321.

Vonmoos, M., Beer, J., and Muscheler, R.: 2006, 'Large variations in Holocene solar activity constraints from ${ }^{10} \mathrm{Be}$ in the GRIP ice core', J. Geophys. Res. 111, doi:10.1029/2005JA011500.

Webber, W. R. and Higbie, P. R.: 2003, 'Production of cosmogenic Be nuclei in the Earth's atmosphere by cosmic rays: Its dependence on solar modulation and the interstellar cosmic ray spectrum', J. Geophys. Res. 108, 1355-1365. 